\title{
ENTREVISTA COM ENÉIAS TAVARES: O STEAMPUNK E A REINVENÇÃO DO PASSADO VISANDO O FUTURO
}

Karla Menezes Lopes Niels

Karla Menezes Lopes Niels

Doutora em Estudos de Literatura pela UFF.

Professora docente I na Seeduc- RJ e professora mediadora no Consórcio CEDERJ/UFF/UAB.

https://orcid.org/0000-0002-3647-2427 


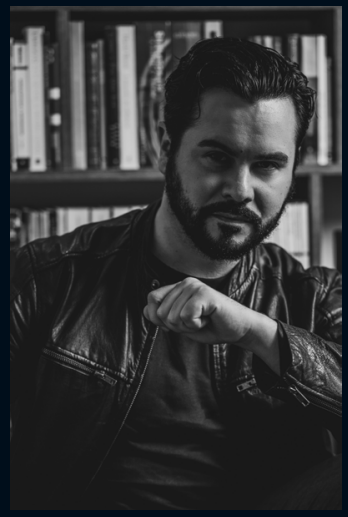

Enéias Tavares é escritor, doutor em Letras pela UFSM e pela University of York, pesquisador do Laboratório Corpus e professor adjunto do Departamento de Letras Clássicas e Linguística da UFSM. Como escritor, estreou em 2014, com a publicação de $A$ lição de anatomia do temível dr. Louison, primeiro volume da série retrofuturista transmídia Brasiliana Steampunk. O romance foi ganhador do Prêmio Fantasy, da Casa da Palavra/LeYa. Em 2017, junto de AZ Cordenonsi e Nikelen Witter, publicou o romance Guanabara Real: A Alcova da Morte, primeiro volume da série de ficção científica e fantasia Guanabara Real, romance que no ano seguinte seria ganhador dos prêmios LeBlanc (Melhor Romance Fantástico de 2017) e AGES (Melhor Romance Juvenil de 2017). Em 2018, publicou, em coautoria com Bruno Anselmi Matangrano, o estudo Fantástico Brasileiro: 0 insólito Literário do Romantismo ao Fantasismo, livro fruto de exposição itinerante homônima que mapeia dois séculos da história da literatura fantástica no Brasil. Ainda, em 2018, ano profícuo para o escritor, lançou, em parceria com o ilustrador Fred Rubim, a HQ A Todo Vapor!, quadrinho em formato Webcomic e impresso, inspirado na série audiovisual homônima que venceu o Global Film Festival Awards Los Angeles 2018 e a Rio Web Fest 2018 em diversas categorias. A série também foi adaptada para cardgame sob o título Cartas a Vapor e para Tarô retrofuturista. Em 2019, publica o romance Juca Pirama: marcado para morrer, que narra a história do protagonista de $A$ Todo Vapor!, além da graphic novel O matrimônio do Céu \& Inferno, de Willian Blake, em parceria com Fred Rubim. No título, transforma o clássico setecentista em uma HQ policial ambientada na São Paulo contemporânea. Em setembro de 2020, lançou, em parceria com Felipe Reis, a primeira série audiovisual steampunk brasileira, via streaming, na plataforma da Amazon Prime Video e, em novembro de 2020, o romance Parthenon Místico. 
A ideia de entrevistá-lo surgiu de meu fazer enquanto professora da educação básica, especificamente, do ensino médio. Nesse, lido com adolescentes de 15 a 18 anos e percebo que, a despeito da resistência que os jovens de hoje apresentam à leitura literária que se apresenta na escola, eles leem. Não gostam de literatura canônica pelo puro e simples fato de não a entenderem, mas demonstram grande abertura a textos literários de cunho mais imaginativo, como é o caso dos gêneros literários que compõem a estética fantástica, entre eles a ficção científica e o steampunk. A literatura que vem sido produzida por Enéias Tavares, por ser não apenas de estética fantástica, mas também multimidiática, chama atenção das novas gerações, ao mesmo tempo que as instiga a conhecer melhor o cânone literário nacional. Sendo assim, vislumbro em sua obra grande potencial para um ensino efetivo de literatura, assim como o próprio autor, cujo projeto "Liga Brasiliana Steampunk" tem justamente este objetivo, contribuir para o ensino-aprendizagem de literatura e para a formação do leitor literário.

Vamos, então, a Enéias Tavares, nosso entrevistado.

\section{P.: O steampunk tem sido definido como um subgênero da} ficção científica, uma espécie de literatura especulativa retrofuturista. Como autor de literatura steampunk, professor e pesquisador de literatura, como você definiria o movimento e a literatura steampunk?

R.: Definições são sempre um desafio e, não raro, incompletas. Sua pergunta, Karla, é precisa ao abordar, no mínimo, duas possibilidades de resposta. Primeiro, é de fato um subgênero de ficção científica, nascido nos mesmos anos e a partir dos mesmos autores de outro subgênero, o cyberpunk, ambas propostas que retiram do punk setentista, isto é, movimento 
que apresenta uma visão de mundo revolucionária e anárquica, possibilidades de explorações ficcionais do futuro, no caso deste, ou do passado, no caso daquele. O steampunk nasceu da obra de três autores - K.W. Jeter, James Blaylock e Tim Powers - que durante a década de 1980 exploraram visões do passado que partiam ou não da literatura - Morlock Night (1979), do primeiro, é uma continuação hipotética da Máquina do Tempo, de Wells -, que revisavam o passado a partir de estereótipos de FC - como é o caso de Homunculos (1986), de autoria do segundo, no qual vilões insanos encontram heróis um tanto idealizados mas construídos de forma irônica - e que ampliavam o passado entrecruzando ficção e história produzindo improváveis e insólitos crossovers - como em Os Portais de Anubis, publicado por Powers em 1983, que entrecruza viagem no tempo, revisão do romantismo inglês e criação de um personagem ficcional, o poeta maldito William Ashblass, que pularia para outras obras, tanto dele quanto de outros escritores. Em suma, literariamente, o steampunk é uma caixinha de surpresas - ou de peculiares engrenagens ficcionais - que permite pastiche de estilos, revisão histórica, recriação de heróis em domínio público, reciclagem de temas passados e presentes, valorização de representatividades e a problematização de assuntos por vezes mais contemporâneos e atuais do que passados.

Em segundo lugar, usas a palavra movimento, o que explicaria o número impressionante de obras publicadas em menos de quatro décadas - em inglês, espanhol e francês, além de português -, sua presença no mundo da música - Abney Park 
e Lindsey Stirling -, dos games - BioShock Infinite e The Order: 1886 -, dos quadrinhos - Liga Extraordinária (ABC Comics) e Steampunk (WildStorm Comics) - do cinema desde As Loucas Aventuras de James West (1999), passando por Van Helsing (2004) e chegando a Mortal Engines (2018) - até o mundo da moda, como nas coleções de Alexander McQueen. Ou seja, todas essas obras, além de dezenas de outras, formam mais que um movimento: dão conta de uma estética que tem sido usada com objetivos diversos e efeitos no mínimo curiosos. Além dessas duas dimensões, literária e estética, se insistirmos na palavra movimento, eu daria como exemplo os eventos, clubes, confrarias e ações executadas por pessoas em diferentes cidades, estados e países, com especial atenção ao Conselho Steampunk de São Paulo, Curitiba e Rio de Janeiro, e a SteamCon de Paranapiacaba, evento que já teve cinco edições e celebra o gênero respeitando essas variadas produções. Então, Karla, encerro dizendo que essa impressão - é gênero literário, movimento cultural ou forma estética? - é justamente o que torna o Steampunk um fenômeno interessante e instigante, sobretudo da perspectiva acadêmica. O que tenho feito, é mais estudá-lo em sua cronologia histórica - o que já fiz em um artigo para a Abusões $^{1}$ - e, usá-lo como laboratório para minha própria produção ficcional, trazendo-o para questões que me intrigam e desafiam no escopo da própria literatura e cultura brasileiras.

1 Disponível em: https://www.e-publicacoes.uerj.br/index.php/abusoes/article/ view/46466. 
P.: Apesar de o estilo Steampunk ter surgido por volta de 1980 nos EUA, em nosso país as primeiras narrativas do gênero apareceram apenas no início dos anos 2000, especificamente, em 2009 com a publicação de Steampunk: Histórias de um Passado Extraordinário, obra organizada e editada por Gianpaolo Celli que contou com diversos autores brasileiros. Desde então o movimento não para de crescer em terras tupiniquins, mas, mesmo assim, ainda devendo considerálo em menor profusão que em países como os EUA e a França, por exemplo. Poderia nos falar sobre a evolução do Steampunk no Brasil?

R.: Eu não sei se concordaria totalmente com o "menor profusão" em relação a outros países. Na verdade, a produção literária brasileira como um todo é de "menor profusão", se relacionada a contextos como o norte-americano e francês, nos quais não apenas o público leitor é consideravelmente maior, como as próprias "estruturas editoriais" bem mais robustas. Levando isso em conta, suspeito que o que vemos desde 2009 em nosso país é bem impressionante. Vejamos o que se fez em uma década. Nos primeiros três anos, temos três coletâneas, Steampunk: Histórias de um Passado Extraordinário, organizado por Gianpaolo Celli (Editora Tarja), VaporPunk: Relatos Steampunk, organizado por Gerson Lodi-Ribeiro e Luís Filipe Silva (Editora Draco), e Steampunk, organizado por Tatiana Ruiz (Editora Estronho), além do romance steamfantasy O Baronato de Shoah: A Canção do Silêncio, de José Roberto Vieira (Editora Draco). Em 2013, temos mais quatro livros: as coletâneas Retrofuturismo, com organização de Romeu 
Martins (Editora Tarja), Deus Ex Machina: Anjos e Demônios na Era do Vapor, com organização de Cândido Ruiz, Tatiana Ruiz e Marcelo Amado (Editora Estronho), e Erótica Steampunk: Por Trás da Cortina de Vapor, com organização de Tatiana Ruiz (Editora Ornitorrinco), além do romance Homens e Monstros: A Guerra Fria Vitoriana (Editora Draco), de Flavio Medeiros Jr. Em 2014. O fato de uma obra steampunk - meu romance, A Lição de Anatomia do Temível Dr. Louison - vencer um concurso literário numa grande casa editorial, a LeYa Brasil, também demonstra o vigor crescente do gênero, que naquele ano também contou com a publicação do segundo romance de José Roberto Vieira, A Máquina do Mundo, e a coletânea VaporPunk II: Novos Documentos, com organização de Fábio Fernandes e Romeu Martins, ambos pela editora Draco. Em 2015, tivemos o primeiro estudo crítico dedicado ao fenômeno steampunk no Brasil, a obra de Éverly Pegoraro, No Compasso do Tempo Steampunk, além do romance Le Chevalier e a Exposição Universal, de A. Z. Cordenonsi, pela AVEC, editora que em 2017 lançaria vários títulos com essa temática, como Guanabara Real: A Alcova da Morte (2017), Vera Cruz (2018), de Gabriel Billy, e Viajantes do Abismo (2019), de Nikelen Witter, obra finalista do Prêmio Jabuti de 2020 na categoria Romance de Entretenimento. No mesmo ano, a Editora Jambô, responsável pelo fenômeno do RPG Tormenta, e a DarkSide Books, uma editora fundamental para o mercado na última década, investiram no gênero steampunk, por exemplo, com Juca Pirama e Parthenon Místico. Ou seja, acredito que o que temos em nosso país é um fenômeno digno de nota, apesar 
de um pouco tardio em relação a outras culturas. Nisso, tua pergunta é bem precisa. Mas, em nosso caso, suponho que seja o tempo de assimilação e de suporte mínimo para o gênero ser conhecido, frutificar e gerar investimentos mínimos, primeiro da parte de editoras pequenas e médias, para depois atingir outras casas editoriais. Neste aspecto, tanto os organizadores de Steampunk, em 2009, quanto de VaporPunk, em 2010, foram sem dúvida pioneiros nessa primeira exploração retrofuturista do nosso passado, uma exploração que está, creio e defendo, apenas começando.

P.: Uma vez que essa revisão retrofuturista está ainda em seu momento inicial, afinal tem cerca de 10 anos, como vislumbra o futuro deste fazer literário no Brasil?

R.: Sendo ousado e um tanto idealista, nossas únicas armas num país sem memória - de história tanto antiga quanto recente distorcida e atacada - e sem grandes investimentos por parte dos administradores, há um Brasil steampunk inteiro para explorarmos juntos, como autores, professores, editores e leitores. Nossa história foi falsificada, nossos costumes silenciados, nossas diferenças étnicas, culturais e sociais foram diminuídas, o que resulta numa desigualdade óbvia, num ódio racial e social assustador e numa violência simbólica e física que a cada semana nos deixa mais perplexos e aturdidos. Como acredito muito no poder transformador da educação, da cultura e da arte, nessa ordem, vejo o steampunk - e essa é a lente que eu uso para me aproximar dele como ferramenta imaginativa - como uma oportunidade de explorarmos nossa cartografia e nossas culturas, de nos aventurarmos na reinvenção de uma 
história que poderia ter sido e numa literatura que ainda está aí para nos ensinar o valor da alteridade. Como o steampunk é também uma brincadeira, um jogo, um convite à criação de histórias insólitas e à fantasia, temos com ele uma liberdade rara quando o assunto é a visitação do passado. Com poucas exceções, a escola nos dá respostas prontas - através dos livros, dos programas e dos debates usuais. O que o steampunk pode fazer é te convidar a olhar o passado com olhar recreativo, criativo e, por fim, crítico. Perdoe-me pelas aliterações, mas cada palavra dessas importa aqui. O steampunk é um entretenimento que te faz viajar no tempo, que diz que você pode possuir a história da sua cidade e do seu estado e recontá-la e, ainda mais, finalmente tentar compreender porque as coisas são do jeito que elas são. Temos uma oportunidade única aqui, e espero que possamos, sobretudo como professores, aproveitá-la, senão num âmbito nacional, num âmbito local mesmo, dentro da nossa sala de aula. Espero que os escritores também levem seus heróis e heroínas para outras paisagens, investindo na representatividade e numa ficção que nos faça voltar à esperança de um Brasil presente e futuro que possamos modificar, alterar e reinventar, algo que o steampunk pode fazer - e faz - com o passado.

P.: Grande parte das narrativas retrofuturistas produzidas no Brasil se empenharam na reescritura e no resgate de um passado não necessariamente brasileiro, mas universal, a exemplo de Homens e monstros: A guerra fria Vitoriana, de Flávio Medeiros Jr. Diante disso, como é ser o primeiro autor a não apenas reciclar nosso passado oitocentista como, 
especialmente, personagens icônicos da literatura brasileira? Como essa realidade alternativa acrescenta à história do nosso país e de nossa literatura?

R.: Nos dois volumes citados, as coletâneas de 2009 e 2010, há uma mescla de elementos, tanto de revisão da história europeia quanto da cultura brasileira. Minha pesquisa visou inicialmente identificar e quantificar nesses contos quais fazem isso e, neste caso, de que modo. Concordo que nesses primeiros contos parece haver mais interesse em explorar tecnologias e histórias tradicionais do que investigar ou até reinventar nossa tradição literária. Mesmo neles, porém, há exceções, como no conto de Roberto de Sousa Causo, "O plano de Robida: Um Voyage extraordinaire", para citar apenas um exemplo. Nele, figuras brasileiras, tanto ficcionais, como Ulisses Brasileiro, quanto históricas, como Santos Dumont, Barão de Mauá, Augusto Zaluar e Padre Landell de Moura, estão presentes. O conto também é interessante pela utilização que faz das nossas paisagens nacionais, partindo de centros urbanos e nos fazendo visitar nossos longínquos territórios selvagens. No caso de minha produção ficcional, é menos uma ideia inédita e mais uma percepção como leitor, e, depois como professor, da dificuldade que temos com nossos clássicos. É um duplo trauma passar pelo ensino médio e depois atuar no ensino de literatura diante de um programa tão engessado de obras obrigatórias e da grande ausência de mediações mínimas que tornem Alencar, Machado e Barreto minimamente atraentes a uma audiência jovem. Nesse sentido, Brasiliana Steampunk nasce mais da observação de que não temos em nosso país a propriedade 
que os ingleses têm, por exemplo, de revisar seu passado histórico e literário - de forma lúdica, heroica e inventiva, como Moore e Newman fazem com seus Liga Extraordinária e Anno Dracula. E, sinceramente, o que nos falta é mediação, pois temos personagens tão fascinantes quanto os de qualquer tradição: pense em Vitória de "Acauã", no Doutor Benignus, em Funesta, nos heróis malditos de Noite na Taverna, nos entediados ou insanos personagens de Machado ou mesmo em sonhadores compulsivos como Sergio e Isaías, entre dezenas de outros. Eu costumo brincar que foram esses personagens que vieram ao meu encontro ao invés do oposto. Na verdade, temos um elenco gigantesco de monstros, fantasmas, heroínas e vilões para explorar. E o mesmo serve para nossa história, que vista através da lente do steampunk, revela-se como um oceano de incongruências sociais, potenciais desperdiçados e líderes fracassados. Ou seja, não vejo o steampunk como literatura escapista de forma alguma. Não que eu tenha qualquer problema com o termo, ao contrário. Antes, é uma ficção que te faz mergulhar na história e na literatura do passado, revisando-a com propriedade e interesse, algo que ainda precisamos aprender, como indivíduos e como cultura, o que acaba complementando minha resposta anterior.

P.: Uma vez que as narrativas retrofuturistas, vez por outra, acabam abordando temas político-sociais atuais, ocasionando uma problematização dessas temáticas, você diria que este tipo de narrativa dialoga com as narrativas distópicas? Como você percebe as aproximações e os distanciamentos entre estes dois fazeres literários? 
R.: O que vale para o romance histórico serve para qualquer outro gênero narrativo, quer ele reinvente o passado, quer o futuro. É o presente da composição que sempre é registrado e ressignificado. Então sim, esses elementos já estão presentes na gênese do steampunk. Jeter, Blaylock e Powers nunca esconderam que seu exercício ficcional esteve perpassado pela obra jornalística seminal de Henry Mayhew, London Labour and the London Poor (1851), um estudo histórico centrado nos marginais do período vitoriano ao invés de suas altas classes e suas cenas excessivamente idealizadas. A essa visão do passado destituído de seu verniz elogioso, se conecta o punk, um movimento contestador e revolucionário que tanto critica e expõe o que está errado na sociedade como propõe uma alteração do status quo, não raro uma proposição perpassada de violência, revolta e subversão. Nesse sentido, o steampunk é tão distópico quanto o cyberpunk, tão contestador quanto obras seminais desse estilo no século XX como Admirável Mundo Novo (1932), 1984 (1948) e Laranja Mecânica (1962). A meu ver, não poderia ser diferente, pois o steampunk é um fenômeno histórico também, nascido da necessidade e da vontade de se colocar o dedo em algumas feridas, como a desigualdade social, o preconceito de gênero, de orientação ou étnico, além dessa onipresente suspeita quanto à autoridade que é uma marca dos nossos tempos.

P.: Em alguns de seus romances como Guanabara real: $A$ alcova da morte, como também na série a $A$ Todo Vapor!, ocorre a união de elementos da ficção retrofuturista, do romance policial e da horror sobrenatural. Essa fusão de gêneros 
e temáticas seria uma característica do steampunk ou é justamente o elemento que difere sua obra das demais?

R.: Eu nem diria que essa aglutinação de gêneros é algo comum ao steampunk - pois acho que não é, apesar de ser bem difícil mapear onde termina a FC e começa o horror; e, onde este termina e dá lugar à crítica social, por exemplo. Também não acho que esse elemento seja um diferencial de minha ficção. Nesse quesito, acho que a questão é outra, que diz mais respeito ao meu processo criativo do que a qualquer intenção inicial de fazer uma coisa ou outra. Guanabara Real parte da sensibilidade de três autores e de suas respectivas escritas e leituras. Então, neste caso, suspeito que tenha sido um resultado narrativo oriundo de unirmos perspectivas diversas a partir de três lentes específicas, que são a ciência de Firmino Boaventura, a investigação de MT Floresta e o misticismo de Remy Rudá. No que concerne à produção individual, estou sempre mais mergulhado na história, na trama e nos personagens do que em gêneros específicos. Juca Pirama é um romance de mistério e crítica social porque seu protagonista me levou a essas searas, sendo a violência presente nele uma remissão direta à sua contraparte lírica. Parthenon Mìstico, por sua vez, é uma narrativa de aventura e também um romance de formação porque nasceu da necessidade de contar a origem desse grupo de anárquicos marginais no Sul do Brasil, como também de reescrever $O$ Ateneu, de Raul Pompeia, um de nossos romances mais desafiadores e mais importantes. Então, acho que é menos uma característica que abarca minha escrita ou então meus planos ficcionais, e mais um hibridismo 
de temas, elementos e situações que cada projeto acaba invocando e reunindo. Eu destacaria que cada um desses livros são também explorações geográficas, uma forma de visitar, mapear, compreender e recriar o Rio de Janeiro em Guanabara, São Paulo em Juca Pirama e Porto Alegre em Parthenon Místico. Há uma cartografia brasileira fantástica nesses livros, e acho que essas diferentes ambientações também alteram substancialmente a trama e as formas como os personagens vivem suas histórias. Quero muito ampliar essa cartografia em futuros livros, levando meus heróis para Brasília, Salvador, Recife e Manaus, entre outras cidades que admiro.

P.: Os personagens de sua obra têm sido retirados de nossa literatura oitocentista, romântica e real-naturalista. Entrementes, apesar de as personagens guardarem algumas características originais, no processo de ressignificação obviamente há uma remodelação desses. Por exemplo, no poema de Gonçalves Dias, I-Juca Pirama é um guerreiro indígena que segue as tradições de seu povo. Por que, em Juca Pirama Marcado para Morrer e na série $\boldsymbol{A}$ todo vapor! o personagem é um magoinvestigador (ou investigador-mago)?

R.: Essa pergunta dialoga tanto com o processo criativo quanto com algumas adequações necessárias a um projeto como Brasiliana Steampunk, que propõe um universo expandido no qual todos os personagens habitam o mesmo país. Primeiro, preciso dizer que meu projeto prevê um mapeamento matemático - e um tanto entediante - das linhas temporais das obras originais. Ainda em 2014, comecei esse mapeamento com uma tabela simples na qual três informações estavam 
presentes: data de publicação, idades hipotéticas dos personagens no enredo e ano de nascimento provável dos personagens. Isso fez com que em Lição de Anatomia eu soubesse, por exemplo, que Sergio Pompeu estava com 33 anos, Vitória Acauã com 30 e Benignus com 76, pra ficarmos com três exemplos. Essa idade foi calculada a partir dos anos de publicações das obras e das idades prováveis dos três, nesse caso 1888 (11 anos), 1893 (12) e 1875 (40). Essa tapeçaria temporal aumentou com os anos e hoje conta com mais de trinta personagens, sobretudo depois de $A$ Todo Vapor!. Grosso modo, é um exercício um tanto simples, uma vez que boa parte dos personagens foi criada nas décadas finais do século XIX. Há exceções, como Solfieri, que tinha aproximadamente 19 anos em 1855, quando Noite na Taverna foi publicado. Como em Brasiliana ele se tornou um satanista imortal, sua idade está congelada e com ele é possível narrar mais de cem anos desse universo. Por outro lado, há - como muito bem mencionaste - Juca Pirama, cujo poema original foi publicado em 1844. Ele apresenta três problemas: a idade hipotética (ele teria mais de 80 anos em 1908, quando $A$ Todo Vapor! se passa), a etnia indígena e, claro, aos que leram o poema de Gonçalves Dias, trata-se de um guerreiro que morre no enredo. Então, neste caso, o que fiz foi levar o poema ao universo de Brasiliana, influenciando a mãe do nosso Juca a nomear seu filho de acordo com os versos de Dias. Mesmo não sendo o mesmo personagem, nosso Pirama também está "marcado para morrer", mas, nesse caso, em meio a mistérios arcanos entre tribos maçônicas na fervilhante selva urbana 
da São Paulo do início do século XX. Por fim, eu também destacaria que Brasiliana Steampunk é constituída, enquanto série - com algumas exceções - de narrativas posteriores aos seus textos fontes. Então é de fato um exercício bem pontual menos de reinventar esses personagens e mais de imaginar os seus destinos em um universo retrofuturista e nesse mundo compartilhado no qual todos habitam.

P.: Diferentemente de Capitu, Vitória não é uma personagem tão conhecida do público brasileiro. Enquanto muitos - mesmos aqueles não afeitos à leitura literária - conhecem acerca da querela se Capitu traiu ou não traiu Bentinho, poucos se lembrarão da peculiar personagem de Inglês de Sousa. Por que a escolha de Vitória? Pode nos falar mais sobre a construção dessa personagem?

R.: Ainda na gênese do projeto, algumas decisões foram tomadas. Acho que ter bem em mente o que eu desejava com esse universo e com esse exercício de reinvenção dos clássicos foi um dos acertos iniciais de Brasiliana, dando unidade e verossimilhança a um mundo que poderia redundar em uma simples bagunça. Além da questão temporal e etária, que apontaria às obras fontes, desejava que os personagens falassem como suas contrapartes literárias. Então, houve também um esforço de ir para os textos fonte vendo o que poderia usar em termos semânticos, discursivos e estilísticos. Já tratei um pouco dessa questão polifônica e literária num artigo para um periódico da PUC-RS, o Scriptorium², e desde então o mesmo tem sido

2 Disponível em: https://revistaseletronicas.pucrs.br/ojs/index.php/scriptorium/article/ view/27991/. 
buscado para todos os personagens. Juca Pirama recria, por exemplo, em estrutura e em estilo, alguns dos versos do poema de Gonçalves Dias, por exemplo. Adicionaria ainda outros dois critérios: o de não assumir que a literatura brasileira se resume aos eixos Rio de Janeiro e São Paulo e a de fugir do panteão exclusivo dos manuais literários. Lição de Anatomia deveria exemplificar isso, tanto por se passar no Sul do Brasil quanto pela mescla de personagens conhecidos, como Simão Bacamarte e Rita Baiana, com outros menos debatidos, como Sergio e Bento d'O Ateneu, e ainda aqueles deixados de lado por muitos professores e leitores, como o Dr. Benignus e para finalmente chegar à sua pergunta - a Vitória de Inglês de Sousa. Quando a descobri, amei a história trágica descrita em "Acauã", o fato dela não ser uma personagem branca e de ter sua origem e poderes relacionados ao norte do Brasil, uma região tão profícua em mitos, histórias e lendas e tão pouco desvendada ou buscada por muitos de nós. Como no conto se trata de uma jovem, de uma adolescente, transpassada não apenas pelo enigma do seu nascimento como também pela maldição de uma série de tabus e interditos, Vitória se tornou um dos pontos altos do romance: Uma mulher de uns trinta anos - em 1911 - forte, poderosa e dona de seu próprio desejo, mas ao mesmo tempo vivendo uma série de conflitos e dúvidas. Vitória é a Esfinge de Lição de Anatomia e uma personagem que, assim como Solfieri, é um prazer escrever, pois ela é absolutamente mutável. No conto "Barcaça de Horrores", a vemos logo depois de Contos Amazônicos. Em Parthenon Místico, ela ainda vivencia seus traumas e 
descobrimos sua passagem pela ilha da Rainha do Ignoto, o que é uma feliz maneira de revisitar e trazer Emília Freitas para nosso universo. Já no conto "Os Súcubos do Inferno", temos uma médium no auge de seus poderes, algo também presente em "Os Espectros do Itaimbé", que conta a passagem dela e Benignus pela cidade de Santa Maria, onde moro. Há pouco, lançamos a timeline de Brasiliana Steampunk ${ }^{3}$, num infográfico comemorativo de seis anos da série. Prevejo em breve fazer o mesmo apenas com os contos de Vitória e com as histórias de Solfieri. No caso dela, há uma "biografia não autorizada" nessas narrativas e uma protagonista fascinante, hipnótica e instigante, epítetos já presentes no conto de Inglês de Sousa.

P.: Além de estar entre os primeiros a reciclar nosso passado tupiniquim através de personagens de nossa literatura, você também é pioneiro ao criar um projeto transmídia, o Brasiliana Steampunk. Poderia nos falar mais sobre este projeto?

R.: Depois que os projetos estão lançados, é um tanto fácil produzirmos uma narrativa do quanto foi tudo cuidadosamente planejado e executado de forma estratégica. A realidade, ao menos neste caso, é outra. Eu não escondo minha fascinação com narrativas para outras mídias - tanto para o audiovisual, quanto para os quadrinhos - nem o quanto esse assunto é um interesse não apenas de criador, mas também de pesquisador. Minha pesquisa de pósdoutoramento na Universidade de Coimbra se concentrou nisso, na literatura fantástica brasileira enquanto potencial transmídia, estudando especialmente o caso de Christopher

3 Disponível em: http://brasilianasteampunk.com.br/infograficos/. 
Kastensmidt e seu próprio universo transmídia, $A$ Bandeira do Elefante e da Arara ${ }^{4}$, um universo que faz o mesmo que Brasiliana enquanto reinvenção da nossa história e da nossa geografia, mas no contexto colonial e mais voltado para o folclore nacional. Por outro lado, enquanto criador, eu também estaria mentindo se dissesse que não tenho um interesse direto por narrativas transmídia, um tema que ainda vai me ocupar por anos, sobretudo com o lançamento de Parthenon Místico, um romance transmídia projetado, desde o início, para comportar uma série de experimentações digitais que transcendem as páginas, e, com os próximos projetos envolvendo A Todo Vapor!. Por outro lado, para voltar ao meu ponto inicial, há muito de oportunidades que surgem, equipes que se formam e projetos que vingam - e outros que não. Há dezenas de ideias, esboços e projetos transmídia e multimídia de Brasiliana, alguns meros rascunhos e outros já bem avançados, que estão nas sombras das gavetas mausoléus do meu gabinete de trabalho. E, talvez eles nunca saiam de lá. Isso para dizer que há sim alguns planos e projetos, mas a vida sempre dá um jeito de colocar pessoas em seu caminho - Felipe Reis, o realizador de $A$ Todo Vapor! é uma delas, Lielson Zeni, o editor da DarkSide que aceitou o desafio e a proposta do Parthenon Místico, outra - ou então de engavetar projetos que tinham tudo para vingar. Note que aqui, Karla, o entrevistado sistemático das respostas anteriores deu lugar a um sujeito imerso no fluxo irregular dos planos abortados e das surpresas editoriais. Produções

4 Disponível em: https://www.eamb.org/brasil/. 
transmídia têm muito disso também e aceitar essa natureza cambiante e incerta é fundamental para não se frustrar ou enlouquecer no processo.

P.: Dentro do projeto da Brasiliana Stampunk, você recentemente lançou, como produção independente, a primeira série de streaming retrofuturista brasileira, A Todo Vapor!, junto a Felipe Reis que, além de atuar como ator, foi diretor e montador da série. Poderia falar um pouco acerca dessa produção audiovisual e do processo de criação/adaptação?

R.: Como um projeto transmídia, trabalhamos menos com adaptações e mais com conteúdos inéditos, criados exclusivamente para as mídias que os acolherão. Se trata de, desde o início, entender que o potencial de uma narrativa literária, essencialmente textual, é diferente de uma história em quadrinhos, que informa seu leitor de uma forma visual e textual, o que por sua vez difere ainda mais do audiovisual, uma mídia bem mais complexa, cara e dependente também de som, música e efeitos especiais, entre outros elementos que a definem. Essa diferenciação é teórica e ideal, uma vez que na prática há uma série de contingências que são, sobretudo, financeiras. E, isso pelo número de pessoas envolvidas. Livros são produzidos por uma pessoa, quadrinhos por duas, além, é claro, das posteriores equipes editoriais. Mas eles tendem a ser projetos mais baratos, mais fáceis de executar. Por outro lado, mesmo numa produção de orçamento limitado como A Todo Vapor! estamos falando de mais de cento e vinte profissionais atuando nas filmagens, na feitura dos figurinos, na criação dos props, na busca e negociação de locações, e, 
ainda na pós-produção, de edição, trilha sonora, cor e efeitos especiais, dimensões que tomam muito tempo e recursos. A Todo Vapor! teve um período relativamente curto de préprodução e filmagens, em torno de um ano, sendo que a pósprodução levou quase dois anos. Tudo isso seria ainda mais desafiador se tivéssemos lidado com uma adaptação ao invés de um roteiro inédito. Custos de produção foram minimizados significativamente em razão disso. De minha parte, foi trabalhar no roteiro e nos bastidores sulistas para termos um romance, web quadrinhos e cartazes, além dos editais que tentamos, todos eles fracassados, com uma única exceção. Enquanto isso, Felipe Reis comandava o show e os desafios diários desses três anos de criação. Para aqueles que quiserem saber desse processo, indico uma entrevista que fiz com ele para o portal CosmoNerd ${ }^{5}$ exclusivamente sobre todos esses segredos, intempéries e surpresas envolvendo uma produção como essa. Agora, o desafio é fazer a série rodar, supervisionar as legendas em inglês e espanhol para o lançamento no mercado internacional, além de buscar alguma parceria que nos auxilie a seguirmos com a série ou com futuros projetos. A Todo Vapor! em breve também ganhará um corte de longa-metragem, 0 que estou adorando fazer em parceria com Felipe Reis. Nossa meta é uma duração de 90 minutos, que pretendemos lançar em algumas salas de exibição - se a pandemia que hoje vivemos possibilitar algo assim, obviamente - e usar para as ações educacionais voltadas para o ensino médio, um dos focos principais de A Todo Vapor!

5 Disponível em: https://cosmonerd.com.br/series/conheca-series/a-todo-vapor-e-oaudiovisual-brasileiro-entrevista-com-felipe-reis/. 
P.: Você acredita que a série $\mathbf{A}$ Todo Vapor!, lançada recentemente via plataforma de streaming da Amazon Prime Video, pode contribuir para a disseminação e evolução do Steampunk no Brasil, bem como de outros gêneros do universo insólito e fantástico? De que forma?

R.: É ainda muito cedo para dizer, pois o lançamento tem poucos meses. Mas obviamente as expectativas são grandes e eu destacaria três pontos. Primeiro, o fato de a série reunir uma legião de heróis literários, apresentados ao público de forma fantástica e lúdica. Há essa cena, no final do terceiro episódio, em que Juca, Capitu, Vitória e Benignus discutem os crimes em Vila Antiga quando são visitados por Aurélia Camargo e Leonardo Pataca. De repente, todos escutam um barulho e quando vão checar sua origem fora da estalagem, dão de cara com Sergio Pompeu e Bento Alves chegando em seu balão. Esse encontro, esse mashup de obras e crossover de personagens, tem um potencial imenso e sugere que finalmente estamos prontos para lidar e até brincar, no melhor sentido do termo, com os personagens da nossa tradição. Em segundo lugar, há uma fatia inteira do nosso público que está acessando o steampunk - e até o gênero fantástico, ao menos o produzido no Brasil - pela primeira vez através da nossa série. Em terceiro, é da série e de uma parceria com a Academia da Trama ${ }^{6}$ que nasceu a comunidade de Brasiliana Steampunk, ${ }^{7}$ formada por criadores, entusiastas e educadores, todos unidos em prol de ações que tanto valorizem o gênero quanto originem ações

6 Disponível em: https://www.academiadatrama.com.br/.

7 Disponível em: https://brasilianasteampunk.com.br/. 
propositivas no campo cultural. Em suma, torcemos todos para a série, e o longa-metragem produzido a partir dela, resultar sim em visibilidade e numa alteração da percepção de que investir em produtos nacionais não seja um bom negócio.

P.: Por fim, vamos falar da escola e da educação? Notamos que boa parte do seu trabalho acaba objetivando ou compreendendo ações educacionais. Isso culmina no seu lançamento mais recente, Parthenon Místico, da DarkSide Books, livro ao redor do qual se desenvolve o projeto escolar "Liga Brasiliana Steampunk". De que trata essa iniciativa?

R.: E voltamos ao início, não? Digo, à escola, afinal, tudo começa lá. Nosso aprendizado do mundo, nossas primeiras interações com pessoas que não são nossos familiares ou vizinhos, nossos conflitos com a hierarquia, nossas descobertas afetivas e também, não raro, nossos traumas mais marcantes e primeiros desafetos. Tudo isso está n'O Ateneu, de Raul Pompeia, uma obra igualmente lírica e experimental, mas também fulcral para entendermos os problemas do nosso sistema educacional. Parthenon Místico presta uma homenagem a esse livro, narrando o que aconteceu com Sergio e Bento quase uma década depois da escola: suas sinas marginais, seus conflitos psicológicos e sociais nesse Brasil do futuro acorrentado ao passado. Em suma, é o livro perfeito para o próximo estágio do universo da série, compreendido no projeto "Liga Brasiliana Steampunk"8 Trata-se de uma iniciativa educacional que compreende kits físicos, com os livros Juca Pirama e Parthenon Místico, além de jogos, quadrinhos e conteúdos exclusivos para professores, 
entre outros materiais físicos e digitais, direcionado aos anos finais do ensino fundamental e ao ensino médio. Esses kits, ou caixas, serão entregues a escolas públicas com o apoio de secretarias de educação, prefeituras e empresas. Ele também tem um braço comercial mais tradicional, voltado a instituições privadas. Mas em suma, a iniciativa significa uma abordagem lúdica, convidativa e transmídia, de aprendermos, ensinarmos e debatermos literatura, história, geografia, artes e patrimônio cultural brasileiro na escola. Cento e trinta anos depois de $O$ Ateneu e do fim tráfico de Raul Pompeia, é uma homenagem que prestamos aos nossos clássicos como também a milhares de professores que batalham dia após dia para levarem educação, cultura e conhecimento aos jovens. 0 projeto começou em Santa Maria, onde uma série de parcerias e um edital público garantirão que - nos meses iniciais de 2021 - todas as escolas do município e do estado recebam um kit físico e packs digitais para cada aluno. Nosso objetivo é, a partir dessa iniciativa piloto, chegar a outras cidades e estados. De minha parte, sou muito feliz em ver as dimensões ficcional e educacional de minha carreira se encontrando num projeto tão especial. 

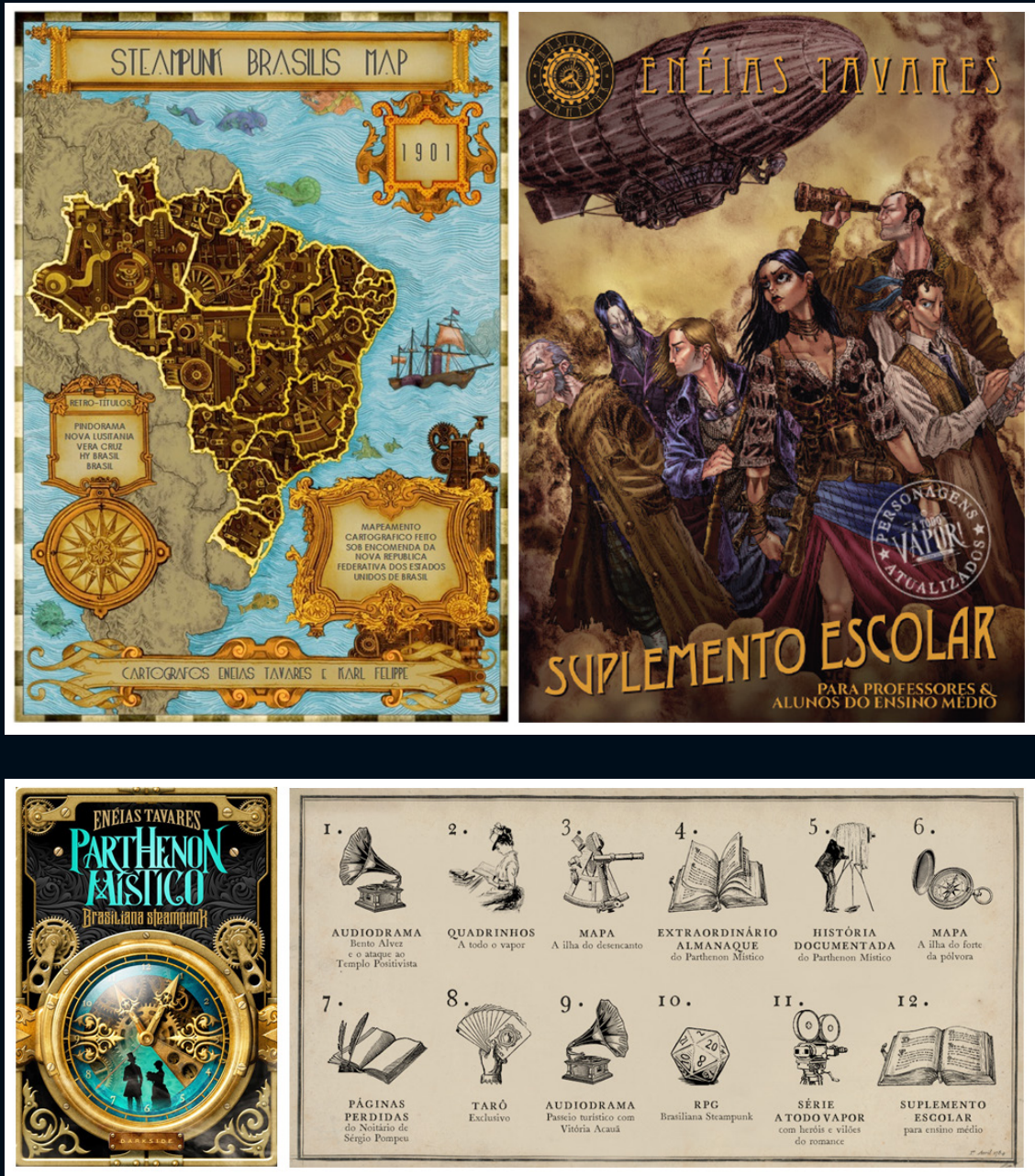